Cuadernos de Lingüística Hispánica $n^{\circ} .28$

ISSN 012 I-053X • ISSN en línea 2346- 1829

Julio-Diciembre 2016, pp. 167-187

\title{
El valor del silencio humano en la cultura escolar*
}

\author{
J. HUMBERTO MOTTA ÁVILA** \\ mottaavila13@yahoo.com
}

Recepción: 27 de julio de 2015

Aprobación: 08 de octubre de 2015

Forma de citar este artículo: Motta Ávila, J.H. (2016). El valor del silencio humano en la cultura escolar. Cuadernos de Lingüística Hispánica, (28), 167-187. doi: http://dx.doi.org/10.19053/0121053X.4914

* Artículo de reflexión derivado de investigación. Presenta un apartado del marco teórico de los avances de la tesis doctoral intitulada La actitud de escucha en la conversación pedagógica de aula.

** Doctorando en Lenguaje y Cultura de la Universidad Pedagógica y Tecnológica de Colombia, Colombia (Uptc); Magíster en Linguística Hispánica; docente de Educación Básica Secundaria y Media, durante 22 años; integrante del Grupo de Investigación EPISTEME (reconocido por Colciencias); actualmente, profesor asesor de práctica pedagógica de la Escuela de Idiomas de la Uptc, Colombia. 


\section{Resumen}

El contenido del presente artículo constituye un apartado del marco teórico de la tesis doctoral del autor, intitulada La actitud de escucha en la conversación pedagógica de aula, indagación que se ubica en el interjuego entre el lenguaje y la cultura, y se focaliza hacia las habilidades comunicativas básicas, profundizando en el fenómeno de la escucha que comparten los sujetos educativos estudiante y docente. El opúsculo se propone poner en escena el alcance de la significación que puede tener el silencio humano en el contexto de la cultura escolar actual, específicamente en la vivencia del aula, marcada por la presencia explícita del ruido y la desescucha; abordar el silencio pedagógico como un acto del lenguaje y como fundamento de la escucha áulica; y mostrar que se hace impostergable la resignificación del silencio humano a través de memes que hagan posible su comprensión y puesta en práctica en la conversación pedagógica de aula y en la comunicación cotidiana de los sujetos educativos.

Palabras clave: cultura escolar, escucha áulica, silencio humano, silencio pedagógico.

\section{The Value of Human Silence for School Culture}

\section{Abstract}

This article is a section of the theoretical framework of the author's doctoral thesis, entitled: The attitude of listening in a classroom pedagogical conversation, a research project located at the interplay between culture and language, and focused on the fundamental communicative skills. This paper delves into the phenomenon of listening, shared by both students and teachers as educational figures. The purpose of this work is to shed light over the significance that human silence can have in the current cultural school context, more specifically, in a classroom experience that is clearly marked by the presence of noise and the absence of a listening culture. Pedagogical silence is addressed as an act of language, the basis for the achievement of classroom listening. Human silence needs to be resignified, comprehended and put into practice not only in the pedagogical classroom conversation but also in the daily communication of all educational figures.

Key words: school culture, classroom listening, human silence, pedagogical silence 


\section{La valeur du silence humain dans la culture scolaire}

\section{Résumé}

Le contenu de cet article constitue une partie du cadre théorique de la thèse doctorale de l'auteur, intitulée L'attitude d'écoute dans la conversation pédagogique de la salle de classe. Cette recherche se trouve dans l'inter-jeu entre le langage et la culture et se focalise vers les habilités communicatives de base, en approfondissant dans le phénomène de l'écoute qui partagent les sujets éducatifs apprenant et enseignant. L'opuscule se propose, d'abord, de mettre en scène la portée de la signification que le silence humain peut avoir, dans le contexte de la culture scolaire actuelle, en particulier dans la coexistence de la salle de classe, encadrée par la présence explicite du bruit et de la non-écoute. Ensuite, d'aborder le silence pédagogique un tant qu'acte du langage et fondement de l'écoute aulique. Et finalement, montrer que l'on ne peut pas remettre à plus tard la ré-signification du silence humain à travers de mèmes qui fassent possible sa compréhension et sa mise en pratique dans la conversation pédagogique de la salle de classe et dans la communication quotidienne des sujets éducatifs.

Mots clés: culture scolaire, écoute aulique, silence humain, silence pédagogique.

\section{O valor do silêncio humano na cultura escolar}

\section{Resumo}

0 conteúdo do presente artigo constitui uma parte do marco teórico da tese doutoral do autor, intitulada La actitud de escucha en la conversación pedagógica de aula, indagação que se localiza no interjogo entre a linguagem e a cultura, e se focaliza nas habilidades comunicativas básicas, aprofundando-se no fenômeno da escuta que compartem os sujeitos educativos, estudante e docente. 0 opúsculo se propõe pôr em cena o alcance da significação que pode ter o silêncio humano no contexto da cultura escolar atual, especificamente na vivência da sala de aula, marcada pela presença explícita do ruído e da não escuta; abordar o silêncio pedagógico como um ato da linguagem e como fundamento da escuta na sala de aula; e mostrar que é impostergável a ressignificação do silêncio humano através de memes que possibilitam sua compreensão e implementação na conversação pedagógica da sala de aula e na comunicação cotidiana dos sujeitos educativos.

Palavras chave: cultura escolar, escuta áulica, silêncio humano, silêncio pedagógico. 
El silencio es un agente comunicador, porque con él se comunican estados de ánimo, sentimientos, pasiones, angustias y alegrías, vivencias intensamente arraigadas en el corazón. Pero, además, el silencio es el punto de partida y el de llegada de toda comunicación verdaderamente humana.

Francesc Torralba

\section{Introducción}

El fenómeno del escuchar ${ }^{1}$ humano y, específicamente, de la escucha áulica, se ha convertido, en la tesis doctoral referida supra, en una aventura investigativa que busca dar cuenta de su complejidad, dada la diversidad de aspectos de órdenes anatomo-fisioneurológicos, filosóficos, musicales, psicológico-psicoanalíticos y pedagógico-lingüísticos que lo componen.

Asuntos como el sentido de la escucha en el aula, la actitud de escucha, la actitud de escucha lingüística, la desescucha y la conciencia para la escucha no han sido tratados en profundidad o sencillamente no han sido estudiados. Si bien, hay estudios serios y significativos como los de Echeverría (2007a, 2007b), Pérez (2012), Corradi (2006), Madaule (2006), Nancy (2007), Novara (2003), Schaeffer (1988) y Tomatis (2010), hace falta tratarlo desde otras ópticas -como la que se plantea en la tesis- en virtud de que el escuchar es el lado oculto o el otro lado del lenguaje, el cual aún no se ha explorado enteramente, circunstancia que lo hace un campo prometedor para la investigación.

Afirmaciones de la literatura especializada, como las siguientes, dan cuenta de ello:

"Normalmente suponemos que para escuchar a otras personas solamente tenemos que exponernos a lo que dicen -debemos estar con ellas, hablarles, hacerles preguntas. Suponemos que haciendo esto, el escuchar simplemente va a ocurrir" (Echeverría, 2007b,

1 De entrada, cabe resaltar la importancia que tiene la audición y el escuchar en el proceso de la comunicación humana trayendo a colación la memorable experiencia de Helen Keller (1933) -sordociega-, quien consideraba la sordera como un problema más profundo y complejo que la ceguera, puesto que esta nos aleja de los objetos, en cambio aquella nos priva del sonido de la voz de las personas que dinamiza el lenguaje y el pensamiento y enciende la llama de la compañía. La desescucha es, precisamente, un factor de alejamiento entre los seres humanos y no es dable su presencia en el aula de clase. Es más, Helen, en ausencia de la audición, desarrolló y contó con una extraordinaria actitud de escucha, en virtud de que, desde una comprensión fenomenológica, el lenguaje trasciende lo verbal. Y precisamente una persona sorda como ella, podría enseñarnos que quizás allí radique el problema de la comunicación en el aula: la necesidad de desarrollar la actitud de escucha. 
p. 142); "En general, alumnos y maestros no solemos tener en cuenta la habilidad de escuchar en la clase de lengua. Seguramente no discutimos su importancia, pero en la práctica no le dedicamos una atención especial" (Cassany, Luna y Sanz, 2011, p. 109); "A los docentes les cuesta cada vez más que sus estudiantes los escuchen y se rinden ante la falta de atención, que se perfila como uno de los principales desencadenantes de los retrasos en el aprendizaje"; "Pero la labor educativa ha subestimado el valor de la escucha. No nos han enseñado a escuchar, y la escucha es un arte tan difícil de ejercer como la palabra, aunque raramente prestemos atención a ella. [...] de ahí que el arte de la escucha sea más básico y fundamental que el de la palabra. [...] La crisis de la receptividad es, al mismo tiempo, la crisis de la civilización" (Torralba, 2007, p. 15). En suma, puede decirse, parafraseando a Segura (2010, p. 1), que el escuchar es la habilidad linguística olvidada tanto en el ámbito escolar como en el familiar y el social.

Por lo antecedente, la ausencia de una formación o de una educación para la escucha ha generado el fenómeno de la desescucha ${ }^{2}$ como una epidemia educativa y social, esto es, como un problema que ocasiona lamentables desperdicios, no solo económicos, sino de aprendizaje y de desarrollo humano, en general.

Así las cosas, y dado lo inconmensurable del fenómeno del escuchar en la actividad humana, la tesis doctoral se ha dedicado a resolver la siguiente pregunta: ¿cuál es el sentido que le atribuyen estudiantes y docentes de Educación Básica Secundaria, de Instituciones Educativas Públicas de Tunja, a la experiencia de escucha lingüistica que realizan en el encuentro pedagógico de aula? En consecuencia, el propósito general es develar los sentidos que le atribuyen estudiantes y docentes a la experiencia de escucha linguística, con el fin de consolidar unos principios de comprensión para una didáctica de la escucha.

Ahora, en el encuadre anterior y en el decurso de la investigación, el silencio aparece como conditio sine qua non pueda darse la escucha linguística en el aula de clase. Pero no se trata del silencio físico o ambiental o ecológico, sino de uno más complejo: el silencio humano, que no solo es físico, sino que además tiene ocurrencia

2 Este término refiere el desvalor de la actitud de escucha. No atañe tanto a lo psicológico, es decir a factores neuronales, como a lo social y cultural. La desescucha viene a ser más un meme introyectado por las prácticas sociales degenerativas, no constructivas, un pacto inconsciente que lleva a los sujetos a acogerse a una costumbre que se enraíza lenta pero segura, hasta hacerse una forma de acción comunitaria. En el paso de la escuela del mutismo a la escuela del bullicio puede verse el desarrollo de dicho meme. En el fondo, constituye una ruptura de paradigma: de los grupos de estudiantes silenciosos y amedrentados a los grupos bulliciosos y temerarios. Cabe aclarar que la desescucha ha estado siempre en la vida social y en la vida de la escuela. Plutarco da noticia de este hecho en su tratado Sobre cómo se debe escuchar. Afirma este pedagogo y moralista clásico que durante la pronunciación de los discursos era común ver y oír a quienes buscaban menospreciar al orador con sus miradas despectivas, sus cuchicheos y sus gestos corporales, su desatención. No lejos de lo que sucede hoy en diferentes escenarios. 
en la interioridad del sujeto de escucha y del sujeto de habla; de este modo, desborda el silencio ecológico y se adentra en los espacios de lo social y cultural. En este sentido, el silencio es un componente esencial de la escucha; por ello, la necesidad de su inclusión y tratamiento en la tesis.

Profundizar en la escucha áulica de manera fenomenológica, lleva, inevitablemente, a la necesidad de una bermenéutica del silencio en el aula de clase, como la plantea Marco (2002, pp. 80-110) para quien el silencio, en la obra de Ortega y Gasset, que él mismo explora, no es solo un fenómeno sociocultural sino lingüístico. Esto mismo pasa en el aula, puesto que escuchar es seguir hablando con el otro en el trasfondo del silencio; es más, en el silencio de cada uno (estudiante o maestro), el lenguaje y la significación se manifiestan más puramente, ya que la intención del hablante se da por entendida para sí mismo. Esto lleva a la conclusión de que el silencio humano en la conversación es un acto del lenguaje: el acto de escucha como acto del lenguaje cobra vida en el acto de silencio. En otras palabras, el silencio en la comunicación humana es un silencio-escucha, un silencio que significa y que es estancia para la construcción de significados en el marco de la interlocución. Pero el silencio áulico, el que comparten estudiantes y docentes, el que valida su conversación pedagógica, solo adquiere su valor lingüístico y semiótico en el entramado de las relaciones sociales, afectivas, comunicativas, entre otras, establecidas en el marco de una cultura escolar, y más específicamente, de una microcultura como es la vida de relación en el aula de clase.

Para dar cuenta de los anteriores asertos, en el presente artículo se trata, en primer lugar, los conceptos de cultura y cultura escolar; segundo, se hace una exégesis del silencio desde diversos autores, a manera de elementos para una fundamentación epistemológica del silencio; y tercero, se presenta un esbozo del silencio humano y el silencio pedagógico en el contexto de la cultura escolar, para dar término con una argumentación acerca del valor lingüístico y semiótico del silencio humano en la cultura escolar, es decir, para mostrar el silencio humano como acto de lenguaje y fundamento de la escucha áulica.

\section{Cultura y cultura escolar}

La razón por la que es preciso tratar primeramente el concepto de cultura, antes que el de cultura escolar, el de silencio y el de escucha, obedece a que estos adquieren su significado y sus sentidos en el contexto de los conglomerados sociales y culturales. Esto quiere decir que el acto de silencio y el acto de escucha están determinados por los modos de comprensión que los sujetos de una cultura (macro, meso o micro) se han permitido construir de tales realidades. No tienen el mismo valor sociocultural el silencio y la escucha en la cultura japonesa que en la cultura colombiana, por dar un ejemplo. Cada 
una los experimenta o vivencia con base en lo que Dawkins (2000, p. 285) denominó memes $^{3}$, los cuales son heredados histórica y espaciotemporalmente.

Por tanto, para tratar el concepto de cultura, esta investigación se vale de las aportaciones de uno de los reformadores del concepto mismo; se trata de Clifford Geertz (2003), quien lo propone, desde una visión semiótica, de este modo:

Creyendo con Max Weber que el hombre es un animal inserto en tramas de significación que él mismo ha tejido, considero que la cultura es esa urdimbre y que el análisis de la cultura ha de ser por lo tanto, no una ciencia experimental en busca de leyes, sino una ciencia interpretativa en busca de significaciones (p. 20).

Considera, además, que la cultura es un documento activo y público "porque la significación lo es" (si no lo fuera, ¿cómo nos comunicaríamos y comprenderíamos?), y que a pesar de constituirse por ideas, "no existe en la cabeza de alguien", y que aunque no siendo física "no es una entidad oculta". De esta manera, "todo el quid de un enfoque semiótico de la cultura es ayudarnos a lograr acceso al mundo conceptual en el cual viven nuestros sujetos [estudiantes y docentes], de suerte que podamos, en el sentido amplio del término, conversar con ellos" (p. 35).

Esta visión de cultura lleva a reconocer que en el estudio de la conducta humana no pueden establecerse predicciones, por lo que la generalización se hace improductiva, dado el carácter cambiante y polimorfo del modo como el ser humano organiza su vida localmente, en cada ecoambiente; en su defecto, entender al ser humano como un animal culturalmente muy variado, lleva a colegir que la observación de una cultura o de un aspecto de una cultura está siempre impregnada "del lugar en que se observa, y de aquello junto a lo que se observa". En otras palabras, "las formas del conocimiento [de una cultura] son siempre ineluctablemente locales", no se pueden separar del instrumental y de los marcos de actuación que el científico utilice (Geertz, 1994, p. 12).

La perspectiva semiótica de Geertz ha tenido impacto en la forma como otros autores actuales entienden la cultura. Por ejemplo, Pérez (2000), al proponer sus conceptos de cultura y de cultura escolar, de alguna manera establece con él puntos de encuentro al considerar una cultura como:

3 Richard Dawkins, en su libro El gen egoísta propone el término meme para dar a entender lo que es "una unidad de transmisión cultural o una unidad de imitación", que puede transferirse de individuo a individuo, de una mente a otra, o de una a otra generación. Creó este neologismo por analogía con gen, como unidad de transmisión biológica. Dada la crítica recibida por Dawkins, debida al rasgo egoísta de la evolución, en la presente investigación se acoge la postura de Joachim Bauer y Mark Ridley quienes sustentan y promueven la perspectiva cooperativa de la evolución biológica y cultural. Así, deberá entenderse acá el meme como una unidad cooperativa de replicación cultural. 
el conjunto de significados, expectativas y comportamientos compartidos por un determinado grupo social, que facilitan y ordenan, limitan y potencian los intercambios sociales, las producciones simbólicas y materiales y las realizaciones individuales y colectivas dentro de un marco espacial y temporal determinado. La cultura, por tanto, es el resultado de la construcción social, contingente a las condiciones materiales, sociales y espirituales que dominan un espacio y un tiempo. Se expresa en significados, valores, sentimientos, costumbres, rituales, instituciones y objetos (materiales y simbólicos) que rodean la vida individual y colectiva de la comunidad (pp. 16-17).

¿Pero cómo se construyen los significados? Pérez ubica este proceso complejo en la conformación de la cultura experiencial de cada sujeto, la cual, en el comienzo de la vida social, inicia por la observación, la imitación y la experiencia directa; luego, con la consolidación del lenguaje, la interacción social del sujeto se amplía, haciendo de la elaboración simbólica el proceso central de construcción de significados. Acompañando lo anterior, se recibe el apoyo de mecanismos y recursos (la adquisición y construcción de guiones, la construcción de conceptos, el desarrollo de estrategias cognitivas, las actitudes y disposiciones, las teorías prácticas). Además, ha de tenerse en cuenta que el desarrollo de la inteligencia se co-implica con el conocimiento y la cultura y "se encuentran distribuidos en la realidad simbólica que constituye la cultura social y no solo en el interior de la mente individual". Es decir, el sujeto construye sus significados a partir de los significados que circulan en el contexto cultural macro, meso y micro.

Actualmente, el contexto posmoderno está signado por unos rasgos que definen la manera como se construyen los significados en las sociedades contemporáneas. Son estos, según Pérez:

La consagración de la propiedad privada, la obsesión por el beneficio particular, la primacía de las leyes de libre mercado, la legitimidad de la competitividad particular a cualquier precio, la obsesión por la eficacia, la primacía de las apariencias, el gusto desmedido por lo efímero y cambiante son componentes ideológicos que junto a la defensa de las democracias formales y la búsqueda de la libertad, la omnipresencia de los medios de comunicación de masas y la posibilidad de superación de las barreras espaciales y temporales a la libre circulación de la información, componen los elementos de la cultura posmoderna (p. 245).

Finalmente, la construcción de significados la apoya Pérez, en las reglas de interacción humana en las instituciones sociales primarias (familia) y secundarias (la escuela y la empresa) del modelo bernsteiniano: las reglas de jerarquía, que "definen la posición y los roles que debe ocupar cada uno de los miembros que se presenta a la comunicación"; las reglas de sucesión y ritmo, que "determinan tanto el progreso de la 
transmisión de significados como la tasa de aprendizaje que es esperable de los individuos de la comunidad", aspecto que está determinado hoy por los medios de comunicación de masas; y las reglas de criterio, que "se refieren a las normas por las cuales el individuo discrimina lo legítimo de lo ilegítimo en la vida social cotidiana” (pp. 247-251).

Respecto de la cultura escolar, Pérez la entiende como a la escuela misma: "un cruce de culturas, que provocan tensiones, aperturas, restricciones y contrastes en la construcción de significados" (p. 12). Así, el hecho de que la cultura escolar sea, simultáneamente, un encuentro de culturas, permite a Pérez resaltar "el carácter sistémico y vivo de los elementos que influyen en la determinación de los intercambios de significados y conductas dentro de la institución escolar [...]" (p. 12).

Las culturas que se entrecruzan en la escuela, según Pérez son: la cultura crítica, alojada en las disciplinas científicas, artísticas y filosóficas; la cultura académica, reflejada en las concreciones del currículum; la cultura social, constituida por los valores hegemónicos del escenario social; la cultura institucional, presente en los roles, normas, rutinas y ritos propios de cada comunidad escolar; y la cultura experiencial, adquirida por cada alumno a través de los intercambios espontáneos con su entorno (p. 17).

Cabe resaltar el hecho de que la influencia de estas culturas en el intercambio y construcción de significados es más potente cuanto más imperceptible sea para los sujetos educativos, pero, a la vez, "sufren de forma inexcusable las implacables determinaciones de la compleja vida contemporánea" (p. 18).

Las ideas hasta aquí expuestas sobre las nociones de cultura y cultura escolar, permiten trazar el horizonte hacia el que se dirige el tratamiento del silencio en el contexto de la vida escolar, puesto que la actitud de escucha está determinada por el valor cultural y linguístico que se le asigne al silencio en la conversación pedagógica.

\section{Elementos para una fundamentación epistemológica del silencio}

Para este cometido, se hace necesario explorar el silencio polifónicamente, en concierto de voces, desde las perspectivas de diferentes autores, con el fin de ganar en complejidad, es decir, para obtener un conocimiento multidimensional de este objeto complejo.

Al hacer un recorrido histórico de las reflexiones acerca del silencio, es necesario distinguir entre el valor o sentido otorgado al silencio en la cultura occidental y en la cultura oriental; en pocas palabras, los estudiosos están de acuerdo en que la palabra se asocia con la primera y el silencio con la segunda. Pero, aunque las referencias bibliográficas 
que apoyan esta aseveración son representativas, es necesario tener en cuenta que en la cultura griega se dan muestras de la importancia que el silencio cobraba en la academia, particularmente en la formación filosófica y en la enseñanza-aprendizaje.

Rasgado (2008) presenta el siguiente itinerario: "Los pitagóricos recuperan el silencio como forma de generar voces más profundas: hacerse las preguntas fundamentales de la filosofía era cuestión de silencio". Incluso, el silencio llegó a ser un método de pensamiento y constituyó una entidad determinante del lenguaje. Luego, en Gorgias de Leontini se advierte que "hay algo en el silencio que solo silencio", es decir, "hay algo existente que no se habla", más allá del hablar-escuchar. Posteriormente, Aristóteles, si bien en Teoría del conocimiento resalta la facultad de la visión, es en Sobre la interpretación en donde "el silencio [la audición] es tocado desde el escuchar"; ahí, el Estagirita afirma que en términos de la aportación al pensamiento, el órgano más contribuyente es el oído (pp. 101-116).

Para seguir el viaje en el tiempo, sobre el camino del silencio, es menester sentar ahora mismo la distinción entre silencio y escucha. El silencio no es la escucha: la escucha requiere del silencio y el silencio requiere ser escuchado para ser comprendido. Sutil diferencia, pero diferencia al fin y al cabo. La razón de mencionarla obedece a que en el curso del tiempo se encuentran importantes obras de reflexión sobre la escucha, que necesariamente contienen alusiones al silencio, pero, en definitiva, no es el interés recabar en este objeto complejo. Como ejemplos, está el Tratado sobre cómo se debe escuchar, de Plutarco (1985, pp. 159-194), en el que el silencio se da por aludido, y El arte de callar, de Abate Dinouart ${ }^{4}$ (1999), obra en la que, entre sus ideas generadoras, se resalta el hecho de que el arte de callar "no es un arte de hacer silencio, sino más bien un arte de hacer algo al otro por el silencio" (p. 11). Pero, basta ya, por el momento, la referencia histórica, para hacer el llamado a los autores que conforman la orquesta actual de estudiosos del silencio, todos moradores de los siglos xx y xxI, varios de ellos latinoamericanos.

Por razones de extensión, de cada uno se acogen solo unas pocas ideas, consideradas centrales para los propósitos de este artículo, intentando tejer una argumentación de cómo se ha ido comprendiendo el silencio en el curso del tiempo.

Es Heidegger quien inaugura en el Siglo xx la reflexión sobre el silencio. Y no lo hace en alguna obra en particular como Ser y Tiempo o Aportes a la filosofía: acerca del evento, sino en toda su obra. Como bien lo afirma Muñoz (2006, p. 7), "el silencio habita de manera silenciosa" en Heidegger; sin embargo, constituye el espacio originario

$4 \quad$ El original de esta obra se publicó en $\mathbf{1 7 7 1 .}$ 
de manifestación del ser: "El silencio es el lugar donde desemboca y se reúne todo el esfuerzo del pensamiento heideggeriano" (p. 11). Para este filósofo, "el silencio significa la máxima expresión de la palabra y la posibilidad máxima de acercamiento al ser" (p. 11).

Por otra parte, el escuchar en Heidegger (1971, p. 185) también es un asunto fundamental, pues, según él, pensar es escuchar el ser, pero desde dentro, desde la escucha pensante, cuyo trasfondo es el silencio. De ahí, su insistencia en que deben darse las condiciones existenciarias de hablar y oír para que alguien pueda escuchar, para que el hablar y el oír se fundan en el comprender. Estas ideas son básicas para la vida del aula y la conversación pedagógica.

El filósofo Picard ([1948] 1971) publica El mundo del silencio, una obra mezcla de filosofía y poesía, en la que aborda el silencio desde múltiples facetas. Entre estas, considera el silencio como un fenómeno absoluto, como un protofenómeno, como el origen de la palabra. En cuanto esto último, dice: "La palabra vino del silencio, de la plenitud del silencio. [...] pero el silencio que precedió a la palabra es el signo de la actividad del espíritu creador: extrae la palabra de la entraña materna del silencio" (p. 19). Afirma, también, que "Cuando dos personas conversan entre sí, siempre está allí un tercero: el silencio que escucha”, lo cual hace del silencio un interlocutor. Además, es reveladora la afirmación de Picard, al agregar que "El silencio puede existir sin la palabra, pero no la palabra sin el silencio", lo que le otorga a su pensamiento un matiz místico (pp. 19-20). Su preocupación es ver cómo la palabra experimenta en la modernidad un grave deterioro, causado por la abundancia y la desconexión con el silencio del cual proviene.

Desde la psiquiatría, Corbella (1987) propone "la necesidad de afrontar el silencio, un silencio como capacidad de descontaminarse de los estímulos ambientales y de escuchar los que germinan en el interior de cada uno" (p. 17), de manera que se dé el encuentro con uno mismo. Por eso, dice:

Reivindico el silencio como una forma más de vida, como una circunstancia vital indispensable para un adecuado encuentro personal y para permitir la posibilidad de desarrollar, con un menor grado de angustia, una vida presente y futura en la cual el individuo tenga una valoración por sí mismo y la búsqueda del ser eclipse la del hacer con una seña de identidad que personalice e individualice (p. 24).

En definitiva, Corbella hace énfasis en el aislamiento del mundanal ruido para que el ser humano se recupere como persona. 
Por su parte, Corradi ([1990] 2006), hace una descripción del silencio, en los siguientes términos:

Si nos conformamos con la creencia aceptada de que el silencio no es ni visto, ni oído, ni "reflexionado", y que, por tanto, es esencialmente algo que no se da, puede ser una preocupación peligrosa intentar "hablar" y, por lo tanto, forzar los límites del lenguaje. El silencio, además, claramente no es una condición en la que uno se encuentra por razones coyunturales o psicopatológicas ya que, como es bien sabido, estos "silencios" se pueden llenar con el estruendo creado por derivados arcaicos y regresivos. El silencio es más como una condición virtual interna a la que podemos aspirar, así como una condición previa para un mayor desarrollo (p. 104). (Traducción del investigador).

El silencio es pues, una aspiración que el ser humano se traza en la perspectiva de construir su propio desarrollo humano; y en tal sentido, es una búsqueda filosófica, en sí mismo.

Ahora, en la compilación que hace Castilla del Pino (1992), intitulada El Silencio, se expone a lo largo de los ensayos la idea del silencio como signo y como forma de conducta, y que en tal condición se caracteriza por la ambigïedad. Frente a esto dice: "Si el habla es polisémica, el silencio es metonimia pura, un camaleón de sentidos" (p. 31). Pero sobresale en el ensayo del propio compilador la concepción del silencio como un hecho, como una acción. A su vez, resalta el hecho de que "Las nuevas generaciones han sido educadas en el horror al silencio y muchos jóvenes son incapaces de concentrarse en una tarea sin tener la radio puesta o la grabadora en marcha", y remata contundentemente afirmando que "La libre opción al silencio es uno de los Derechos Humanos no escritos en las declaraciones oficiales cuya exigencia se está haciendo más urgente" (pp. 35-36). Nótese en esto último, la fuerza con que los medios de comunicación de masas han influido en la psiquis de la infancia y la juventud, creando una cultura del ruido.

Por otro lado, el argentino Fernando Onetto (1998), desde una perspectiva axiológica, expresa su preocupación por la sobreabundancia de palabras, de mensajes propositivos y proyectivos del tiempo cultural actual, asunto que impide la instalación de la persona en su presente, esto es, en la dimensión de su estar. Por eso, declara que "No es nuevo decir que en nuestra sociedad que ha idolatrado el discurso o, mejor, los discursos, la lingüística, hay mucha palabra y poca escucha. [...] Hay poca libertad para dejar que la palabra hable con todos sus significados" (p. 144). Ante esto, puede decirse que el consumo de lenguaje sonoro de distintas naturalezas tiene, para el sujeto humano, el destino trágico del hastío. Para resolver esto, en el espacio escolar, Onetto propone enseñar el silencio, en la medida en que las experiencias de los estudiantes con 
el silencio, como recurso de aprendizaje de la sabiduría -entendida como "un saber que reúne diferentes notas: corporal-intelectual, situado-universal, de memoria-de proyecto, de los límites-del misterio" (p. 138)-, les permite: tomar contacto con el mundo interior, escuchar la experiencia de los otros, contemplar la naturaleza, la multitud y el sentido de la inmensidad, y madurar las decisiones.

En breve, es necesario que la cultura escolar haga del aula un espacio experiencial del silencio y la escucha activos, de manera que no sea solo el salón para las clases, sino un lugar de aprendizajes, donde sea posible la convivencia en el marco del respeto por la diversidad y la diferencia, y un lugar en el que se construya la vida social y cultural.

Nancy ([2002] 2007), por su parte, se refiere al silencio en estos términos:

"El silencio", en efecto, debe entenderse aquí no solo como una privación, sino como una disposición de resonancia: un poco -y hasta exactamente- como cuando, en una condición de silencio perfecto, uno oye resonar su propio cuerpo, su aliento, su corazón y toda su caverna retumbante (p. 45).

Como se ve, Nancy busca el silencio interior que no termina de rebotar en su permanente reverberar.

En el atardecer del siglo xx, Le Breton (2001) ofrece una significativa aportación a la reflexión sobre el silencio. Pone en escena la crisis actual de lo social, que es la misma crisis del silencio, extendida por "la disolución mediática del mundo [que] genera un ruido ensordecedor, una equiparación generalizada de lo banal y lo dramático que anestesia las opiniones y blinda las sensibilidades" (p. 5). Actualmente, puede preverse el impacto de esto en la vida social de la escuela y el aula.

Frente a este estado de cosas, Le Breton propone "una ética de la conversación que dé por sentado que todo enunciado reclama una respuesta, toda afirmación un argumento que la avale y todo diálogo una deliberación mutua" (p. 6). Esto es, entender el silencio como una forma del significado, pues "en la conversación el silencio permite a la palabra alcanzar su plenitud" (p. 8).

Con Torralba (2001), el silencio se entiende como "un agente comunicador, porque con él se comunican estados de ánimo, sentimientos, pasiones, angustias y alegrías, vivencias intensamente arraigadas en el corazón". Y añade: "Pero, además, el silencio es el punto de partida y el de llegada de toda comunicación verdaderamente humana" (p. 24).

Desde la perspectiva pedagógica, considera que "el silencio es el gran ausente de los procesos educativos" (p. 54) y que el estudiante en el aula aprende gramática, "pero 
no aprende a callar ni a compartir la experiencia silente con sus compañeros" (p. 55). Esto deja ver el malestar que se vive actualmente en la escuela del ruido.

Marco (2009) recientemente ha dado a conocer la profunda crisis de la escuela, resultado de equivocadas interpretaciones de la libertad y de las normas que regulan la convivencia en las escuelas, hasta tener un sistema educativo que raya en el delirio, pues en el aula de clase se "eliminó todo sentido de disciplina, orden y esfuerzo personal". Bajo este estatuto, el maestro fue aniquilado en su función de constructor social, pero, irónicamente, también se desvaneció la función re-creativa del estudiante. Tal estado de cosas, reclama la presencia de un mediador: el silencio activo, como lo denominó Freire ${ }^{5}$ (2002), generador de participación y promotor de una ética de la comunicación pedagógica que haga posible el re-encuentro de los sujetos educativos con su cultura, en su máxima expresión.

Finalmente, Didier (2010), desde una orientación del crecimiento espiritual, propone una pedagogía del silencio que recupere al ser humano de la actual edad del ruido que lo ha despersonalizado. Para él, el silencio es algo positivo que se caracteriza por no encontrarse en el sistema de producción de bienes, por no ubicarse en el mundo de lo utilitario, por no ser un objeto de supermercado, sino por "producir" personas (p. 47). Para lograr esto, es necesario un cambio profundo en la educación, que modifique su finalidad, sus métodos y sus contenidos; es menester que "desde la infancia el niño se habitúe al desarrollo permanente de la atención consciente y voluntaria" (p. 30), de manera que pueda habitar en la palabra, en el lenguaje del que está hecho. Por esto, para que la palabra del ser humano sea genuina debe provenir del silencio, "puesto que el silencio es el verdadero útero de la palabra" (p. 11). Así, una pedagogía del silencio es a la vez una pedagogía del encuentro del sujeto consigo mismo, con su proyecto de trascendencia y con los demás seres humanos y la naturaleza.

Llegado este punto del presente apartado, puede considerarse que esta somera exégesis constituye un boceto de una fundamentación epistemológica del silencio, desde diferentes campos, dada su naturaleza compleja; pero, principalmente, como algo que tiene que ver con lo linguístico y lo semiótico de la comunicación, en general, y de la comunicación pedagógica, en particular.

5 "Estoy en un profundo silencio activo", respondió Freire en una ocasión en la que los asistentes de una reunión le preguntaron por qué había permanecido tan callado, si se esperaba de él su entera participación. El sentido de "participación" que conlleva esta expresión del pedagogo brasilero, se aclara en la anécdota que se narra en el prólogo de su libro Pedagogía de la esperanza. 


\section{El silencio humano y el silencio pedagógico en la cultura escolar: el silencio pedagógico como acto del lenguaje y fundamento de la escucha áulica}

Para comprender la necesidad de plantear el concepto de silencio bumano es preciso partir del concepto de silencio físico o ambiental u objetivo. Este último, propiamente es inexistente en un ecoambiente natural, pues aun estando en una cámara anecoica o sala insonorizada queda el remanente acústico del cuerpo humano del sujeto que da cuenta del fenómeno, y que de hecho respira y palpita. Por lo que el silencio físico es inexistente para el escucha. Según Pardo (2009), esto lo descubrió Cage ${ }^{6}$, para quien "El significado esencial del silencio es la pérdida de atención... el silencio no es acústico... es solamente el abandono de la intención de oír". Frente a esta afirmación, es necesario entender que el silencio que escuchaba Cage era el del ambiente de la cámara anecoica, del cual su cuerpo era parte.

Por la anterior razón, surge la necesidad de proponer el concepto de silencio bumano, con el fin de hacer referencia a la existencia de un fenómeno silencioso activo en todo sujeto, un silencio interior que genera la actitud de escucha, un silencio que no es la ausencia del habla sino posibilidad de la misma tanto en el escuchante como en el hablante. Es un silencio inserto en la cultura, un hecho social. Y, también, un silencio en el ser, parafraseando a Heidegger. Este silencio es el que permite entender el escuchar como una actitud lingüística (de un sujeto capaz de lenguaje), y la actitud de escucha como una postura ética y política del sujeto discursivo, en el marco de una conversación.

Queda claro que el silencio humano se distancia del silencio físico, porque donde sucede el fenómeno silencioso es en el ser humano mismo. El silencio humano, puede darse en el sujeto o en el grupo, es individual y social.

Este silencio hacedor de la escucha es un silencio significativo; por eso, es un silencio cultural (el silencio es portador de significado y este se toma de la cultura o se construye en la enculturación) que requiere, indefectiblemente, del silencio ecológico: no se habla ni se escucha genuinamente en condiciones de polución acústica.

En el contexto escolar, el silencio pedagógico es el silencio humano aplicado a los fines de la educación, de la enseñanza y del aprendizaje, por parte de los sujetos educativos, estudiante y docente. Es el desempeño de "la función del silencio respecto de

6 John Cage fue un músico norteamericano que realizó una prueba para experimentar el "silencio total", pero se dio cuenta en la cámara anecoica de la Universidad de Harvard, que era poco probable de lograr, visto que en el ambiente de la cámara, su cuerpo producía sonidos: su respiración, el latido de su corazón y su sangre fluyendo por las venas. 
la escucha" como expresa Foucault (2005, p. 386), pero en un ambiente interactivo, lo cual lo diferencia de la aplicación de un ejercicio de mera memoria.

Ahora, el hecho de que el silencio, así entendido, signifique e implique un tipo de actividad del sujeto, lo hace, por un lado, partícipe de las características del signo, y por otro, una clase de acto de lenguaje. Como signo, participa de funciones como: ilocutiva, porque conlleva una intención; perlocutiva, visto que produce unos efectos o reacciones en el interlocutor; locutiva, ya que el silencio habla; fática, puesto que el silencio es un puente de contacto entre las voces; poética: la retórica del silencio da cuenta de esto. Además, con Castilla del Pino (1992, p. 83), puede afirmarse que el silencio es ambiguo, tanto que es necesario desambiguarlo develando las condiciones del contexto. También, como afirma Fierro (1992), el silencio como conducta humana forma una unidad con la palabra,

se introduce en el interior de la palabra y del discurso en la figura de cortes y pausas que separan y articulan las unidades verbales. En eso, el silencio constituye un fenómeno esencialmente lingüístico, no solo como límite del lenguaje, sino también como elemento interno suyo (p. 48).

Complementariamente, el silencio, como fenómeno comunicativo complejo, desborda las posibilidades de lo linguístico y se adentra en lo semiótico. Esto ocurre cuando el silencio acompaña otros sistemas simbólicos como el gesto, o cuando el significado del silencio hay que extraerlo de los componentes puramente culturales, o del inconsciente, visto que este está estructurado como lenguaje, según la concepción de Lacan -citado por Catilla del Pino (1992, p. 19)-.

Cabe decir, entonces, que el silencio tiene un valor lingüístico y un valor semiótico. Por el primero, es un acto del lenguaje que se evidencia en el acto de habla y en el acto de escucha. Por el segundo, constituye memes impresos en la cultura que llevan a los sujetos de una comunidad a comportarse comunicativamente de una forma peculiar.

Como acto del lenguaje, el silencio se une al acto de habla para hacer posible el acto de la comunicación. En este sentido, Burke (2001, p. 155), asevera que "Guardar silencio es en sí mismo un acto de comunicación". Con esto, es posible entender que el silencio es actividad y que el silencio como pasividad es un mito, toda vez que el sujeto siempre está haciendo (comunicando) algo con el silencio.

El silencio humano es acto porque es un hecho en la realidad subjetiva, y es un acto de lenguaje, lingüístico y semiótico, por su propia naturaleza sígnica y simbólica. El ser humano silente permanece en el lenguaje porque habita en él, como lo ha hecho saber 
Maturana (2008, p. 11). Este argumento garantiza la existencia del acto de silencio como acto de lenguaje.

Finalmente, el silencio pedagógico, como acto de lenguaje que está convocado para fluir incesantemente en la comunicación pedagógica, deviene en fundamento de la escucha, ya que sin aquel, esta no se da en el ambiente áulico.

El silencio pedagógico hunde sus raíces en la cultura de la sociedad en la que se inserta determinada cultura escolar; está dinamizado en la escuela por el tejido de significados que cada uno de los integrantes de la comunidad escolar ha apropiado para sí como cultura experiencial. En un grupo clase, opera el mismo principio, con la diferencia de que en tal microcultura se da la expresión de una idiosincrasia que le da identidad particular como grupo atento y participativo, autorregulado, un concierto de voces y silencios que se constituyen en la perspectiva de su propio desarrollo 0 , un grupo desconcertante. Es esto último lo que ha acicateado la investigación sobre la desescucha y la propuesta de la necesidad de una educación para la escucha.

En las actuales condiciones de degradación de la palabra y del silencio en la vida en las aulas, la educación para la escucha formaría parte de una contracultura que busca redimir y libertar al ser humano de las cadenas de la cultura del ruido y la polución sonora. El silencio pedagógico sería una opción subversiva, dado que lo común y corriente es la desescucha generalizada que oprime la vida personal y social.

El silencio pedagógico en el aula no deberá ser un hecho impuesto, ni un silencio como lo tácito; en un avance cultural, el silencio pedagógico deberá ser una decisión autónoma, producto de la enculturación. Tampoco ha de ser una mordaza, sino la condición sin la cual puede realizarse la conversación pedagógica. El silencio en el aula es un silencio edificante para la cultura escolar, por eso, en el aula no debe darse la "ley del silencio", pues esto no es ni ético ni humanizador.

El silencio hacedor de la escucha áulica es un silencio interior y ambiental a la vez. Es interior como condición sin la cual el sujeto de discurso pueda escuchar; si el ruido interior (voces interiores, distracciones, espíritu viajero, etc.) mora la actitud, es poco probable que se dé la escucha efectivamente; es exterior o ambiental, en la medida en que cualquier perturbación distinta a las voces en conversación intencionada interfiere en la masa de ondas sonoras que percibe el sistema auditivo, generando debilidades en la percepción y la comprensión.

El silencio de la escucha (o en la escucha) no es el silencio de la escritura ni de la literatura; aquel es un silencio dejado a la relación hablante-escucha, es un silencio que 
relaciona, es un silencio en relación. El silencio en la escucha, esto es, en la comunicación, es un silencio que mora en el sujeto-escucha; no es el silencio del cosmos, ni el silencio mítico; es un silencio que habita al sujeto, y que el sujeto, a su vez, habita, para hacer posible la trayectoria de la palabra, en la perspectiva de descifrar los sentidos que porta desde el hablante.

La experiencia del silencio en el aula debe asumirse como un derecho-deber, no como algo que pueda mendigarse o esperarse en dependencia de las migajas que los bulliciosos quieran dejar caer al oído. Los memes actuales han generado la comprensión en el estudiante de que el educador es cualquier sujeto y el aula cualquier espacio para hacer cualquier cosa (las cosas que se vengan a buen talante); en este sentido se ha deseducado, se han hecho elaboraciones erróneas. Una nueva cultura deberá otorgar los nuevos valores para la vivencia en el aula. El aula está lejos de desaparecer como recinto físico y como espacio simbólico de la interacción educativa, y las consecuencias de la instrucción desde la casa mediante artilugios tecnológicos, ya mostró sus resultados. Entonces, es imperativo recuperarla para los estudiantes y los maestros, para el silencio pedagógico y la escucha áulica; ¡es inaplazable liberar al estudiante, al maestro y el aula misma de la ensordecedora cultura del ruido! En suma, hay que reconstruirla desde la comunicación edificante y la cultura.

\section{Conclusiones}

La cultura escolar como entramado de significados, resultado de las interacciones de los sujetos educativos con el mundo experiencial, a niveles local y global (medios de comunicación masivos) determina la forma como han de darse y asumirse los comportamientos humanos en la comunidad; entre ellos el uso del lenguaje. En este uso del lenguaje (la comunicación), el silencio es un fenómeno de particular importancia, pues define el éxito de los actos de habla. Por tanto, hay que explorarlo desde una óptica interdisciplinaria para que el conocimiento multidimensional dé cuenta de su extraordinaria complejidad y puedan heredarse nuevos memes cooperativos a las generaciones de escolares, en beneficio de la transformación y el mejoramiento de la vida comunitaria, actualmente en crisis.

El silencio, más que un fenómeno físico, ecoambiental u objetivo, es un fenómeno subjetivo, determinado por los componentes culturales de una sociedad o una comunidad. Por eso, se ha hecho necesario proponer el concepto de silencio humano, para identificar el silencio que brota del sujeto y que es la génesis de la actitud de escucha. El modo como 
se encara la escucha por un determinado sujeto o un grupo, depende de los componentes acumulados en la cultura experiencial de cada integrante.

En el estado actual de la escuela y, por ende, del aula, se hace necesario que los conceptos de silencio humano y silencio pedagógico cobren vida; es decir que entren a formar parte de los memes cooperativos necesarios para la transformación de los procesos de interacción pedagógica. Así, el silencio como acto de lenguaje podrá cumplir sus funciones linguística y semiótica. De esta manera, la perspectiva de una educación para la escucha que recupere el valor del silencio en el aula, no busca el acallamiento de las voces, sino, justo lo contrario, demanda por la presencia de un silencio profundamente activo que haga posible la expresión y la escucha -que devienen participación- de todas las voces que habitan el aula, realidad que solo puede darse en la trama y la urdimbre del silencio.

La educación para la escucha podrá atenuar la desescucha que se vive en las aulas como crisis generalizada de la cultura escolar, porque para la vida escolar la crisis del silencio no es una crisis sino La Crisis. No hacerlo, es una decisión irresponsable desde las políticas macro hasta las políticas micro. La ausencia de una educación para la escucha ha causado paulatinamente que la mayoría de los sujetos educativos se haya unido a las hordas de la indiferencia, de la frustración o de la propia contaminación auditiva en el ecoambiente humano del aula. De ahí que sea inaplazable la resignificación del silencio, en la vida escolar, cometido que constituye una empresa formidable ética y estética, visto que la activación del silencio en la escuela del ruido resulta ser hoy una propuesta subversiva: se requiere de valentía, en el docente y en el estudiante, para reclamar la franja de silencio que haga posible el derecho a escuchar y a ser escuchado activamente en el encuentro de aula, en condiciones de dignidad y respeto, 0 , incluso, para habitar el silencio, tan necesario para recuperarse de la fatiga producida por el incesante ruido físico y psicológico de la vida escolar moderna.

\section{Referencias bibliográficas}

Burke, P. (2001). Hablar y callar. Funciones del lenguaje a través de la historia. (Trad. Alberto L. Bixio). Barcelona: Gedisa.

Castilla del Pino, C. (1992, comp.) El silencio. Madrid: Alianza.

Cassany, D., Luna, M., y Sanz, G. (2011). Enseñar lengua. (15ª reimpresión). Barcelona: Graó.

Corbella, J. (1987). Miedo al silencio. Buenos Aires: Folio. 
Corradi, G. ([1990] 2006). The other side of language: A philosophy of listening. London: Routledge.

Dawkins, R. (2000). El gen egoísta. Barcelona: Salvat.

Didier, N. J. (2010). Pedagogía del silencio. Buenos Aires: Brujas.

Dinouart, A. (1999). El arte de callar. Madrid: Siruela.

Echeverría, R. (2007a). Actos del lenguaje: la escucha. Buenos Aires: Granica.

Echeverría, R. (2007b). Ontología del lenguaje. Buenos Aires: Granica.

Fierro, A. (1992). La conducta del silencio. En Castilla del Pino. El silencio (pp. 47-78). Madrid: Alianza.

Foucault, M. (2005). La bermenéutica del sujeto. Clase del 17 de marzo de 1982, Primera hora. Madrid: Akal.

Freire, P. (2002). Pedagogía de la esperanza: Un reencuentro con la pedagogía del oprimido. México: Siglo XXI.

Geertz, C. (2003). La interpretación de las culturas. Barcelona: Gedisa.

Geertz, C. (1994). Conocimiento local: Ensayos sobre la interpretación de las culturas. Barcelona: Paidós Ibérica.

Heidegger, M. (1971). Ser y tiempo. México: FCE.

Keller, H. (1933). Helen Keller in Scotland: a personal record written by herself. London: Methen \& Co. Recuperado de: https://en.wikiquote.org/wiki/Helen_Keller

Le Breton, D. (2001). El silencio. Madrid: Sequitur.

Madaule, P. (2006). Terapia de escucha: Una solución para mejorar la atención, el lenguaje, el aprendizaje y la comunicación. ( $2^{\mathrm{a}}$ ed.). México: Trillas.

Marco, Á. (2002). Una hermenéutica del silencio. Revista de estudios orteguianos, (4), mayo de 2002. Recuperado de http://www.ortegaygasset.edu/fog/ver/453/revista-de-estudiosorteguianos/numero-4-mayo-de-2002/articulos/una-hermeneutica-del-silencio-enortega).

Marco, Á. (2009). El silencio en la enseñanza: Las hieles de un sistema educativo delirante. Barcelona: PPU.

Maturana, H. (2008). La democracia es una obra de arte. Bogotá: Magisterio-Mesa Redonda. 
Muñoz, R. (2006). Tratamiento ontológico del silencio en Heidegger. Madrid: Fénix.

Nancy, J-L. ([2002] 2007). A la escucha. Buenos Aires: Amorrortu.

Novara, D. (2003). Pedagogía del saber escuchar. Hacia formas educativas más democráticas y abiertas. Madrid: Narcea.

Onetto, F. (1998). Con los valores ¿quién se anima? Buenos Aires: Bonum.

Pardo, C. (2009). Del tiempo suspendido. Recuperado de: http://home.att.ne.jp/grape/charles/dc/ dc_texts/pardo-del_tiempo_suspendido.pdf

Pérez, Á. I. (2000). La cultura escolar en la sociedad neoliberal. Madrid: Morata.

Picard, M. ([1948] 1971). El mundo del silencio. (Trad. Norberto Silvetti Paz). Caracas: Monte Ávila Editores.

Plutarco (1985). Obras morales y de costumbres (Moralia), Tomo I. Madrid: Gredos.

Rasgado, A. A. (enero-junio, 2008). Filosofía del silencio. Signos Lingüísticos, IV (7), 101-116. Recuperado de http://tesiuami.uam.mx/revistasuam/signoslinguisticos/include/getdoc. php?id=97

Sacks, O. (1990). Veo una voz: Viaje al mundo de los sordos. Barcelona: Anagrama.

Segura, J. A. (2010). El escuchar, la habilidad lingüistica olvidada. Recuperado de: http:// www.buenastareas.com/ensayos/El-Escucha-La-Habilidad-Ling\%C3\%BC\%C3\%ADsticaOlvidada/756390.html

Schaeffer, P. (1988). Tratado de los objetos musicales. Madrid: Alianza.

Tomatis, A. (2010). El oído y la voz. Badalona: Paidotribo.

Torralba, F. (2007). El arte de saber escuchar. Lleida: Milenio.

Torralba, F. (2001). El silencio: un reto educativo. Madrid: PPC. 